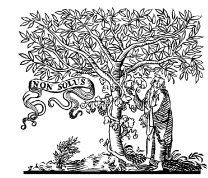

ELSEVIER

\title{
EDITORIAL
}

\section{Letter From the Chair}

It is my great pleasure to serve with colleagues that are at the forefront of fostering multidisciplinary wound care. They not only keep pace with the new technology and application to patient care, but are leaders in our field. This year we have partnered with AMP for our membership meeting and the celebration of the 10th anniversary of the American College of Clinical Wound Specialists!

We were again able to engage our membership as ambassadors and educators to South America, teaching 4 courses this spring and summer. In addition, we partnered with Kindred to deliver a tailored course for their team. The ACCWS Seal of Excellence, which is and will continue to be an incredible asset to our members and our Industry partners, vets products through the engagement of our Scientific Committee. The review information is available to assist our members in decision making and moving practice patterns forward based on evidence. Our Journal continues to publish articles that review and utilize new products and algorithms and will soon be available electronically.
The ACCWS continues to grow in membership across all disciplines. With the addition of our IT specialist, the ACCWS web page has become more member friendly look us up on FaceBook or Linked-In. The power of networking multiple disciplines is now available. We are here to help you grow individually, host a Back to Basics Course or link up with a local colleague!

I hope to see you all in Chicago at the AMP meeting August 12-15th!

Tammy Luttrell, MSPT, PhD, CWS, FACCWS

Chair of ACCWS,

Director of Rehabilitation, Director of Lions Out Patient Burn Center, Director of Out Patient Wound Center, University Medical Center, 1800 West Charleston Blvd., Las Vegas, NV, USA

E-mail address: tammy_luttrell@msn.com 